BMJ Open Diabetes Research \& Care

\title{
Vitamin D for the treatment of painful diabetic neuropathy
}

\author{
Abdul Basit, ${ }^{1,2}$ Khalid Abdul Basit, ${ }^{1}$ Asher Fawwad, ${ }^{1,2}$ Fariha Shaheen, ${ }^{1}$ \\ Nimra Fatima, ${ }^{1}$ Ioannis N Petropoulos, ${ }^{3}$ Uazman Alam, ${ }^{4}$ Rayaz A Malik ${ }^{3,4}$
}

To cite: Basit A, Basit KA, Fawwad A, et al. Vitamin D for the treatment of painful diabetic neuropathy. BMJ Open Diabetes Research and Care 2016;4:e000148. doi:10.1136/bmjdrc-2015000148

- Additional material is available. To view please visit the journal online (http://dx. doi.org/10.1136/bmjdrc2015-000148)

Received 8 August 2015 Revised 12 October 2015 Accepted 13 November 2015

\section{(1) CrossMark}

${ }^{1}$ Baqai Institute of Diabetology and Endocrinology, Karachi, Pakistan

${ }^{2}$ Baqai Medical University, Karachi, Pakistan

${ }^{3}$ Weill Cornell Medicine-Qatar, Qatar Foundation, Doha, Qatar

${ }^{4}$ Centre for Endocrinology and Diabetes, Institute of Human Development, University of Manchester and the Manchester Royal Infirmary, Central Manchester Hospital Foundation Trust, Manchester, UK

Correspondence to Professor Rayaz A Malik; rayaz.a.malik@manchester.ac. uk

\section{ABSTRACT}

Objective: To assess the effect of high-dose vitamin $D$ in patients with painful diabetic neuropathy. Methods: A single intramuscular dose of $600000 \mathrm{IU}$ vitamin $D$ was administered, and the effects on metabolic parameters and neuropathic pain assessed over 20 weeks.

Results: 143 participants with predominantly type 2 diabetes, aged $52.31 \pm 11.48$ years, with a Douleur Neuropathique 4 (DN4) score $(3.0 \pm 1.8)$, total McGill pain score $(21.2 \pm 14.9)$, and Short Form McGill Pain Questionnaire (SFMPQ) score $(2.1 \pm 0.9)$, were enrolled. The baseline 25-hydroxyvitamin D $(25(\mathrm{OH}) \mathrm{D})$ level was $31.7 \pm 23.3 \mathrm{ng} / \mathrm{mL}$ and $58(40.5 \%)$ patients showed evidence of vitamin $D$ deficiency $(25(\mathrm{OH}) \mathrm{D}<20 \mathrm{ng} / \mathrm{mL})$. Intramuscular administration of vitamin $\mathrm{D}$ resulted in a significant increase in $25(\mathrm{OH}) \mathrm{D}(46.2 \pm 10.2 \mathrm{ng} / \mathrm{mL}$, $p<0.0001)$ and a reduction in positive symptoms on the DN4 $(p<0.0001)$, total pain score $(p<0.0001)$, and SFMPQ $(p<0.0001)$

Conclusions: Treatment with a single intramuscular dose of $600000 \mathrm{IU}$ of vitamin $\mathrm{D}$ in patients with painful diabetic neuropathy is associated with a significant decrease in the symptoms of painful diabetic neuropathy.

Trial registration number BIDE-12/2014.

\section{INTRODUCTION}

A large population-based study has recently shown that the prevalence of painful diabetic neuropathy (PDN) is $\sim 21 \%$, and painful symptoms are more prevalent in patients with type 2 diabetes, females, and South Asians. ${ }^{1}$ PDN is characterized by symmetrical lower limb paresthesiae, dysesthesiae, lancinating pains and allodynia, with nocturnal exacerbation $^{2}$ and significant sleep disturbance, with a reduced quality of life. ${ }^{3}$ National and international guidelines advocate a range of therapies for symptom relief. ${ }^{4} 5$ However, the therapeutic efficacy for all recommended medications is at best $\sim 50 \%$ pain relief and is limited due to unwanted side effects. ${ }^{2}{ }^{6}$ Apart from peripheral and central alterations, ${ }^{7}$ metabolic alterations such as increased glycemic flux ${ }^{8}$ and elevated plasma methylglyoxal levels have been implicated in the pathogenesis of PDN. ${ }^{9}$
Key message

- Vitamin D may play an important role in the treatment of painful diabetic neuropathy.

- A single high-dose intramuscular injection of vitamin $D_{3}$ provides significant relief in painful diabetic neuropathy.

- The benefits of vitamin $D$ were maximal at 10 weeks and lasted for the period of the 20-week study.

Several recent observational studies in patients with diabetes have demonstrated a significant association between vitamin D deficiency, and paraesthesiae and numbness, ${ }^{10}$ but also between neurological deficits and electrophysiology ${ }^{11}{ }^{12}$ as well as parasympathetic dysfunction. ${ }^{13}$ Furthermore, a recent systematic review and meta-analysis of 1484 patients with type 2 diabetes has demonstrated a highly significant association (OR -2.68) between vitamin $\mathrm{D}$ deficiency and the development of diabetic peripheral neuropathy. ${ }^{14}$ A more detailed study using electrophysiology and Douleur Neuropathique 4 (DN4) scores has shown that serum levels of vitamin $\mathrm{D}$ are significantly reduced while serum vitamin D-binding protein (VDBP) and vitamin D receptor (VDR) levels are comparable between diabetic patients with and without peripheral neuropathy. ${ }^{15}$ Recently, the FIELD study, a multinational undertaking, has shown that vitamin $\mathrm{D}$ deficiency was present in $50 \%$ of 9795 patients with type 2 diabetes and it predicted microvascular outcomes. ${ }^{16}$

There is, of course, an association between vitamin $\mathrm{D}$ deficiency and painful symptoms in the general population. ${ }^{17}$ In relation to a mechanistic link between vitamin $\mathrm{D}$ and pain, a recent study has shown that nociceptive calcitonin gene-related peptide-positive neurons have a distinct vitamin $\mathrm{D}$ phenotype with hormonally regulated ligand and receptor levels. ${ }^{18}$ Vitamin D deficiency results in increased numbers of axons containing CGRP and, in culture, VDR expression is increased in growth cones and sprouting 
appears to be regulated by VDR-mediated rapid response signaling pathways. ${ }^{19}$ Nerve Growth Factor (NGF) is known to be depleted in experimental diabetes $^{20}$ and, in a study of patients with diabetic neuropathy, NGF immunostaining on skin keratinocytes correlated with skin axon-reflex vasodilation, a measure of small fiber neuropathy. ${ }^{21}$ In an experimental study, NGF expression was maintained in sciatic nerves of diabetic animals treated with a vitamin D analog (CB1093). Similarly, tacalcitol, active vitamin $\mathrm{D}_{3}$, induces NGF production in human epidermal keratinocytes. ${ }^{22}$ Treatment with vitamin $\mathrm{D}_{3}$ has been shown to reduce demyelination in a cuprizone experimental model of demyelination $^{23}$ and, in a separate spinal cord compression model, it has been shown to induce axonal regeneration. ${ }^{24}$

In relation to the potential therapeutic benefits of vitamin D therapy, studies are limited. An open-label prospective study in 51 patients with type 2 diabetes and painful neuropathy showed that $\sim 2000$ IU of cholecalciferol daily for 3 months resulted in an $\sim 50 \%$ decrease in the visual analog scale (VAS). ${ }^{25}$ Recently, in a placebo controlled study of 112 patients with type 2 diabetes randomized to $50000 \mathrm{IU}$ of cholecalciferol once weekly for 8 weeks, there was a significant increase in $25(\mathrm{OH}) \mathrm{D}$ and an improvement in the Neuropathy Disability Score (NDS), but no change in NDS nor in neurophysiology. ${ }^{26}$

Given the mechanistic link between vitamin D and neuropathy, and the known prevalence of vitamin D deficiency, particularly in South Asians with diabetes, we have now undertaken a single-center open-label clinical trial to determine the effects of a single high-dose administration of intramuscular vitamin $\mathrm{D}$ on symptoms of PDN.

\section{MATERIALS AND METHODS}

\section{Study design and participants}

This prospective open-labeled study was conducted between June 2012 and April 2013, in the Baqai Institute of Diabetology and Endocrinology (BIDE) in Karachi, Pakistan.

\section{Ethics statement}

Ethical approval for the study was obtained from the Institutional Review Board (IRB) of BIDE. Study participants gave signed informed consent, in keeping with the Declaration of Helsinki.

\section{Inclusion criteria}

All patients with type 1 or type 2 diabetes, aged 1880 years, with a glycated hemoglobin (HbAlc) level $\leq 11 \%$ at the screening visit, were considered eligible to participate in the study.

\section{Exclusion criteria}

Patients with renal impairment, or hypothyroidism or hyperthyroidism; patients currently taking vitamin D supplementation, or antiepileptic or antituberculous medication; patients with a previous or current problem of primary or tertiary hyperparathyroidism, hypercalcemia, psychiatric disorder, alcohol dependency, Hepatitis B or C, HIV infection or peripheral neuropathy due to a non-diabetic cause; pregnant or breastfeeding female patients; patients allergic to nuts or any nut products and patients participating in any other interventional research trial, were excluded from the study.

\section{Assessment}

Patients underwent assessment at baseline and on four subsequent visits every $5 \pm 1$ week, such that the second, third, fourth, and fifth visits occurred at 4-6; 8-12; 1416 and $18-20$ weeks, respectively.

\section{Data collection}

Blood pressure, weight, and height were recorded at all visits. The 25-hydroxyvitamin $\mathrm{D}(25(\mathrm{OH}) \mathrm{D})$ serum calcium $(\mathrm{Ca})$, HbA1c, fasting blood glucose, and creatinine, were assessed at the screening (visit 1, V1) and the last visit (V5) of the study. Medications for PDN were not changed throughout the study.

\section{PDN assessment}

Six questions that reflected positive symptoms for pain on the DN4 Neuropathic Pain Diagnostic Questionnaire, those being questions $1,2,3,4,5$, and 10 (sensations of burning, painful cold, electric shocks, tingling, pins and needles, and brushing, respectively), were assessed in all participants at each visit. The Short Form McGill Pain Questionnaire (SFMPQ) was evaluated to establish the sensory dimensions of pain, which included pain sensations such as throbbing, shooting, stabbing, sharp, cramping, gnawing, hot, burning, aching, heavy, tender, and splitting; and affective dimensions of the pain experience, which included sensations such as tiring-exhausting, sickening, fearful, and punishingcruel. ${ }^{27}$ The primary efficacy parameter was the change in total McGill pain location (higher numbers indicating more severe pain) and McGill pain score.

\section{Administration of vitamin $D_{3}$ injection and measurement of 25(OH)D}

A single intramuscular dose of $600000 \mathrm{IU}$ of vitamin $\mathrm{D}_{3}$ was administered at V1 by paramedical staff in accord with the results of a recent study indicating a good therapeutic effect with this dose. ${ }^{28}$ The laboratory used internal quality controls for the measurement of 25 $(\mathrm{OH})$ vitamin D. Serum $25(\mathrm{OH}) \mathrm{D}$ was measured using an immunoenzymometric assay, based on a solid phase ELISA performed on microtiter plates, and was performed exactly per the manufacturer's instructions.

The cross-reactivity for vitamin $\mathrm{D}_{2}$ (of the assay) as per manufacturer's assertion was $100 \%$ (relative to vitamin $\mathrm{D}_{3}$ ) and the assay has excellent correlation to existing globally recognized assays, in combination with good sensitivity and precision (EP17-A Protocols for 
Determination of Limits of Detection and Limits of Quantitation; Approved Guideline, STANDARD published by Clinical and Laboratory Standards Institute). The linear range of the assay is $7.7-122.9 \mathrm{ng} / \mathrm{mL}$. Interassay and intra-assay variation of the in-house control was $2.5 \%$ and $9.2 \%$, respectively.

Vitamin D levels were categorized as deficient (25 $(\mathrm{OH}) \mathrm{D}<20 \mathrm{ng} / \mathrm{mL}$ ), insufficient (25(OH)D 20-30 ng/ $\mathrm{mL})$, and sufficient $(25(\mathrm{OH}) \mathrm{D}>30 \mathrm{ng} / \mathrm{mL}){ }^{29}$

\section{STATISTICAL ANALYSIS}

Data analyses were conducted on StatsDirect (Altrincham, Cheshire, UK). All continuous variables, namely, age, weight, height, body mass index, systolic and diastolic blood pressure, and biochemical variables, are presented as mean $\pm \mathrm{SD}$. Analysis of variance (ANOVA) and paired Student $t$ test or non-parametric counterpart were used depending on the normality of the data. All participants enrolled into the study were included in subsequent analyses with missing data handled by using the last observation carried forward (LOCF) for pain scores. Regression analyses were undertaken between baseline 25(OH)D status and total McGill pain location, McGill pain score, DN4, and positive symptoms at baseline. $p$ Value $<0.05$ was considered statistically significant and maintained for multiple comparison tests.

\section{RESULTS}

Table 1 shows the baseline demographic, clinical, anthropometric, and biochemical variables of the study population. In total, 143 participants with predominantly type 2 diabetes aged $52.31 \pm 11.48$ years with a DN4 score $(3.0 \pm 1.8)$, total McGill pain score $(21.2 \pm 14.9)$, and SFMPQ score $(2.1 \pm 0.9)$, were enrolled. The baseline 25 $(\mathrm{OH}) \mathrm{D}$ level was $31.7 \pm 23.3 \mathrm{ng} / \mathrm{mL}$ and $58(40.5 \%)$ patients had evidence of vitamin D deficiency $(25(\mathrm{OH})$ $\mathrm{D}<20 \mathrm{ng} / \mathrm{mL}$ ).

\section{Loss to follow-up}

Seven participants did not complete to V5. The final visit before dropout is as follows: two participants at V4, one participant at V3, one participant at V2, and three participants had been seen only at V1. All participants enrolled into the study were included in subsequent analyses with LOCF used for pain scores.

\section{Biochemistry}

Comparing V1 with V5, 25(OH)D levels increased significantly $\quad(31.7 \pm 23.3 \mathrm{ng} / \mathrm{mL}$ to $46.2 \pm 10.2 \mathrm{ng} / \mathrm{mL}$, $\mathrm{p}<0.0001)$. There was also a significant reduction in HbAlc $(8.6 \pm 1.5 \%$ vs $8.2 \pm 1.5 \%, \mathrm{p}=0.02)$ and increase in high-density lipoprotein (HDL) ( $39 \pm 10$ vs $43 \pm 11 \mathrm{mg} / \mathrm{dL}$, $\mathrm{p}=0.03$ ), with no change in total cholesterol and no change in triglycerides. There was a small but significant increase in serum Ca levels $(\mathrm{p}=0.009)$ (table 2).
Table 1 Baseline characteristics of patients

\begin{tabular}{|c|c|}
\hline Baseline characteristics & Total \\
\hline $\mathrm{n}$ & 143 \\
\hline Age (years) & $52.3 \pm 11.50$ \\
\hline Male gender $n(\%)$ & $59(41)$ \\
\hline \multicolumn{2}{|l|}{ Type of diabetes } \\
\hline Type 1 & $7(4.9 \%)$ \\
\hline Type 2 & $136(95.1 \%)$ \\
\hline Duration of diabetes (years) & $12.1 \pm 7.60$ \\
\hline Body mass index $\left(\mathrm{kg} / \mathrm{m}^{2}\right)$ & $29.7 \pm 5.8$ \\
\hline Systolic BP (mm Hg) & $126 \pm 16$ \\
\hline Diastolic BP (mm Hg) & $80 \pm 9$ \\
\hline Hypertension $(B P \geq 130 / 85$ mm Hg) & $73(51.0 \%)$ \\
\hline Fasting plasma glucose $(\mathrm{mg} / \mathrm{dL})$ & $158.5 \pm 71.2$ \\
\hline Serum creatinine $(\mathrm{mg} / \mathrm{dL})$ & $0.98 \pm 0.30$ \\
\hline Calcium (mg/dL) & $8.7 \pm 0.6$ \\
\hline Serum cholesterol (mg/dL) & $169 \pm 41$ \\
\hline Triglyceride (mg/dL) & $134 \pm 80$ \\
\hline High-density lipoprotein (mg/dL) & $39 \pm 10$ \\
\hline Low-density lipoprotein (mg/dL) & $106 \pm 34$ \\
\hline $\mathrm{HbA1c}(\%)$ & $8.6 \pm 1.5$ \\
\hline $\mathrm{HbA1c}(\mathrm{mmol} / \mathrm{mol})$ & $70.2 \pm 16.4$ \\
\hline $25(\mathrm{OH}) \mathrm{D}(\mathrm{ng} / \mathrm{mL})$ & $31.7 \pm 23.2$ \\
\hline Deficient $(<20 \mathrm{ng} / \mathrm{mL})$ & $58(40.6 \%)$ \\
\hline Insufficient (20-30 ng/mL) & $24(16.8 \%)$ \\
\hline Sufficient (>30 ng/mL) & $61(42.7 \%)$ \\
\hline
\end{tabular}

\section{Total McGill pain location}

Total McGill pain location changed significantly between $\mathrm{V} 1$ and V2 $(\mathrm{p}=0.001)$, with a further significant reduction at V3 $(\mathrm{p}<0.0001)$, V4 $(\mathrm{p}<0.0001)$ and V5 $(\mathrm{p}<0.0001)$ compared with V1 (table 3, supplementary fig 1 ).

\section{McGill pain score}

The McGill pain score did not change between V1 and V2 ( $p=$ not significant (NS)), however, there was a significant reduction at V3 $(\mathrm{p}<0.0001), \mathrm{V} 4(\mathrm{p}<0.0001)$, and V5 $(\mathrm{p}<0.0001)$, compared with V1 (table 3 , supplementary fig 1).

\section{Douleur Neuropathique 4}

There was no significant change in the DN4 score between V1 compared with V2, V3, V4, and V5. However, when the positive symptoms of the DN4 score were compared, there was no change between V1 and V2 $(p=N S)$, but there was a significant reduction at V3 $(p=0.0005)$, V4 $(p=0.001)$, and V5 $(p=0.0003)$, compared with V1 (table 3, supplementary fig 1 ).

\section{Questionnaire scores stratified on vitamin D status}

There was an improvement in pain scores that was independent of baseline vitamin D status. Comparing patients based on deficient/insufficient vitamin D status $(25(\mathrm{OH}) \mathrm{D} \leq 30 \mathrm{ng} / \mathrm{mL})$ and sufficient vitamin $\mathrm{D}$ status $(25(\mathrm{OH}) \mathrm{D}>30 \mathrm{ng} / \mathrm{mL})$, there were no differences 
Table 2 Change in anthropometric and metabolic parameters after administration of vitamin D

\begin{tabular}{|c|c|c|c|}
\hline Parameters $(n=143)$ & Pretreatment baseline & $\begin{array}{l}\text { Post-treatment } \\
\text { week } 20\end{array}$ & p Value \\
\hline Body mass index $\left(\mathrm{kg} / \mathrm{m}^{2}\right)$ & $29.7 \pm 5.8$ & $30.2 \pm 7.1$ & NS \\
\hline Systolic blood pressure (mm Hg) & $126 \pm 16$ & $123 \pm 15$ & NS \\
\hline Diastolic blood pressure $(\mathrm{mm} \mathrm{Hg})$ & $80 \pm 9$ & $78 \pm 7$ & NS \\
\hline $\mathrm{HbA1c}(\%)$ & $8.6 \pm 1.5$ & $8.2 \pm 1.5$ & 0.02 \\
\hline $\mathrm{HbA1c}(\mathrm{mmol} / \mathrm{mol})$ & $70.2 \pm 16.4$ & $66.1 \pm 16.6$ & \\
\hline Creatinine (mg/dL) & $0.98 \pm 0.30$ & $1.01 \pm 0.35$ & NS \\
\hline Calcium (mg/dL) & $8.7 \pm 0.60$ & $8.9 \pm 1.0$ & 0.009 \\
\hline Serum cholesterol (mg/dL) & $169 \pm 41$ & $162 \pm 43$ & NS \\
\hline Triglycerides (mg/dL) & $134 \pm 80$ & $136 \pm 78$ & NS \\
\hline High-density lipoprotein (mg/dL) & $39 \pm 10$ & $43 \pm 11$ & 0.03 \\
\hline Low-density lipoprotein (mg/dL) & $106 \pm 34$ & $100 \pm 34$ & NS \\
\hline $25(\mathrm{OH}) \mathrm{D}(\mathrm{ng} / \mathrm{mL})$ & $31.7 \pm 23.2$ & $46.2 \pm 10.2$ & $<0.0001$ \\
\hline
\end{tabular}

between pretreatment baseline scores and V5 scores for total McGill pain location, McGill pain score, DN4, and positive symptoms. However, there was a significant reduction in total McGill pain location $(\mathrm{p}<0.0001$ and $\mathrm{p}<0.0001)$, McGill pain score $(\mathrm{p}=0.002$ and $\mathrm{p}=0.0002)$, and positive symptoms $(\mathrm{p}=0.05$ and $\mathrm{p}=0.002)$, when comparing pretreatment baseline scores to V5 scores within the stratified groups (deficient/insufficient vitamin D status $(25(\mathrm{OH}) \mathrm{D} \leq 30 \mathrm{ng} / \mathrm{mL})$ and sufficient vitamin D status $(25(\mathrm{OH}) \mathrm{D}>30 \mathrm{ng} / \mathrm{mL})$ (table 4$)$.

\section{Regression analyses}

There were no significant correlations between $25(\mathrm{OH})$ D status with either total McGill pain location, McGill pain score, DN4 or positive symptoms at baseline.

\section{DISCUSSION}

The present study adds to the limited data on the potential benefits of vitamin D therapy on PDN. While this study shows that a significant proportion of patients with diabetes in Karachi have vitamin D deficiency, the overall level of vitamin $\mathrm{D}$ in this population is higher than previous studies from Pakistan, indicating that a significant proportion had previously received vitamin D replacement from their primary physician. ${ }^{30-34}$ This may explain the relatively weak but significant association between the levels of vitamin D and the severity of PDN, confirming the findings from the National Health and Nutrition Examination Survey, ${ }^{10}$ and a study from Kuwait. ${ }^{11}$

The administration of 600000 IU of vitamin D results in a modest but significant increase in 25(OH)D levels measured at 20 weeks. This improvement in $25(\mathrm{OH}) \mathrm{D}$ levels was associated with an improvement in several independent measures of PDN, which became significant at V3, approximately 10 weeks after administration of vitamin $\mathrm{D}$. This would argue against a placebo effect, as this would have been expected to manifest immediately or at least at V2. Furthermore, a maximal placebo response from baseline of $33-36 \%$ has been shown in double-blind randomized controlled trials ${ }^{35}$ and our data show improvement of pain far in excess of a placebo response. However, we cannot exclude a placebo response particularly as patients received regular follow-up after a known active intervention. Previously, a prospective study of 51 patients with type 2 diabetes from Australia reported a significant reduction in VAS from 3.3 to 1.7 and SFMPQ score from 32.1 to 19.4. ${ }^{25}$ Similarly, in a randomized, placebo controlled, double-blind trial of QR-333, a topical compound (containing vitamin $\mathrm{D}_{3}$ ), reduced numbness, jolting pain, and irritation from baseline values, with an overall

Table 3 Pain and neuropathic pain measures from baseline to final visit with significance at each visit

\begin{tabular}{|c|c|c|c|c|c|}
\hline Pain and neuropathy measures & Pretreatment baseline & V2 & V3 & V4 & V5 \\
\hline Total McGill pain location & $21.3 \pm 15.0$ & $19.1 \pm 15.9$ & $7.5 \pm 7.5^{\star}$ & $6.5 \pm 6.4^{*}$ & $5.9 \pm 5.3^{*}$ \\
\hline Median (IQR) $(-/ 45)$ & $23(7-36)$ & $13(5-36)$ & $5(2-11)^{*}$ & $5(2-9)^{*}$ & $5(3-8)^{\star}$ \\
\hline McGill pain score $(-/ 5)$ & $2.1 \pm 0.9$ & $1.9 \pm 1.0$ & $1.7 \pm 1.1^{\mathrm{a}}$ & $1.5 \pm 1.0^{\star}$ & $1.5 \pm 1.0^{*}$ \\
\hline DN4 & $3.0 \pm 1.8$ & $2.8 \pm 2.1$ & $2.6 \pm 1.9$ & $2.8 \pm 2.1$ & $2.8 \pm 2.1$ \\
\hline Median (IQR) (-/10) & $3(2-4)$ & $3(1-4)$ & $2(1-4)$ & $3(1-4)$ & $3(1-4)$ \\
\hline Positive symptoms (DN4) & $2.0 \pm 1.4$ & $1.7 \pm 1.5$ & $1.5 \pm 1.4 \#$ & $1.4 \pm 1.4^{\wedge}$ & $1.4 \pm 1.2^{\star *}$ \\
\hline Median (IQR) $(-/ 6)$ & $2(1-3)$ & $1(1-3)$ & $1(0-2)$ & $1(0-2)$ & $1(0-2)$ \\
\hline
\end{tabular}

${ }^{*} \mathrm{p}<0.0001,{ }^{a} \mathrm{p}=0.007, \# \mathrm{p}=0.03, \wedge \mathrm{p}=0.006,{ }^{*} \mathrm{p}=0.004$.

DN4, Douleur Neuropathique 4; V2, visit 2. 
Table 4 Pain and neuropathic pain measures for baseline and final visit stratified on vitamin D status with significance at each visit

\begin{tabular}{|c|c|c|c|c|c|c|c|c|}
\hline \multirow{2}{*}{$\begin{array}{l}\text { Baseline } \\
\text { vitamin D } \\
\text { status }\end{array}$} & \multicolumn{2}{|c|}{$\begin{array}{l}\text { Total McGill pain } \\
\text { location } \\
\text { Median (IQR) (-/45) }\end{array}$} & \multicolumn{2}{|c|}{$\begin{array}{l}\text { McGill pain score } \\
\text { Median (IQR) }(-/ 5)\end{array}$} & \multicolumn{2}{|c|}{$\begin{array}{l}\text { DN4 } \\
\text { Median (IQR) (-/10) }\end{array}$} & \multicolumn{2}{|c|}{$\begin{array}{l}\text { Positive symptoms } \\
\text { (DN4) } \\
\text { Median (IQR) (-/6) }\end{array}$} \\
\hline & $\begin{array}{l}\text { Pretreatment } \\
\text { baseline }\end{array}$ & V5 & $\begin{array}{l}\text { Pretreatment } \\
\text { baseline }\end{array}$ & V5 & $\begin{array}{l}\text { Pretreatment } \\
\text { baseline }\end{array}$ & V5 & $\begin{array}{l}\text { Pretreatment } \\
\text { baseline }\end{array}$ & V5 \\
\hline$<30 \mathrm{ng} / \mathrm{mL}$ & $21.9 \pm 15.0$ & $6.2 \pm 6.3^{*}$ & $2.0 \pm 0.9$ & $1.5 \pm 1.0^{* \star}$ & $2.8 \pm 1.8$ & $2.8 \pm 2.0$ & $1.9 \pm 1.5$ & $1.4 \pm 1.2^{\mathrm{a}}$ \\
\hline$(n=80)$ & 23.5 (6-37) & $5(3-8)$ & $2(1-3)$ & $1.5(1-2)$ & $3(1-4)$ & $3(1-4)$ & $2(1-3)$ & $1(0-2)$ \\
\hline$\geq 30 \mathrm{ng} / \mathrm{mL}$ & $20.6 \pm 15.1$ & $5.6 \pm 3.8^{*}$ & $2.2 \pm 1.0$ & $1.6 \pm 0.9 \sigma$ & $3.3 \pm 1.7$ & $3.1 \pm 1.8$ & $2.1 \pm 1.4$ & $1.4 \pm 1.1^{\star \star}$ \\
\hline$(n=63)$ & $19(7-36)$ & $5(3-8)$ & $2(2-3)$ & $1(1-2)$ & $3(2-4)$ & $3(2-4)$ & $2(1-3)$ & $1(0-2)$ \\
\hline
\end{tabular}

improvement in measures of quality of life. ${ }^{36}$ A recent case report on a patient with PDN who had been refractory to treatment with tricyclic's, gabapentin, pregabalin, and oxycodone, showed a dramatic improvement in neuropathic symptoms after treatment with 50000 IU of vitamin $\mathrm{D}_{2}$ weekly. ${ }^{37}$ Furthermore, recently, a placebo controlled trial of oral vitamin $\mathrm{D}$ in type 2 diabetes has shown a significant reduction in the Neuropathy Symptom Score with no change in the NDS or neurophysiology. ${ }^{26}$ The improvement in pain in our study seems to be independent of the baseline vitamin D status, with no difference in pretreatment and V5 pain scores in those with adequate vitamin D status ( $\geq 30 \mathrm{ng}$ / $\mathrm{mL}$ ) compared with those who have insufficient/deficient vitamin D status $(<30 \mathrm{ng} / \mathrm{mL})$. The exact reason for this effect, independent of vitamin D status, remains to be elucidated, however, possible rationale for it may include changes in Ca signaling, neurotrophic factors, and production of active metabolites. ${ }^{22}{ }^{38-39}$ While in vitro and in vivo studies have shown that vitamin $\mathrm{D}$ is neurotrophic, and regulates neuronal growth and differentiation, ${ }^{22} 39$ the doses and duration of treatment in the previous study may be insufficient to improve neuropathic deficits, per se.

Lower serum vitamin D level have been associated with a higher HbAlc ${ }^{40}$ and lower HDL levels. ${ }^{41}$ In the current study, we show small but significant improvements in HbAlc and HDL. Thus an additional potential mechanism of benefit may be via the reduction in HbAlc and increase in HDL, observed in this study. Of note, there was a small increase in serum $\mathrm{Ca}$, which was not clinically significant.

Treatment options for PDN are currently limited due to side effects from many of the current therapies. We acknowledge that a major limitation of the current study is the lack of a placebo group. However, a single highdose of intramuscular vitamin $\mathrm{D}$ appears to be a safe and effective treatment for PDN. A longer placebo controlled study with more frequent assessment of vitamin D levels and objective measures of neuropathy is required to assess the optimal frequency, dose safety, and overall efficacy of vitamin D in PDN, and, perhaps, in diabetic neuropathy.

\section{CONCLUSION}

A single intramuscular dose of 600000 IU of vitamin D appears to be a safe and efficacious treatment for PDN over 20 weeks.

Contributors $A B$ contributed to the concept and design, and clinical and neurological assessment, and reviewed the manuscript. KAB was the study coordinator, researched the data and wrote the manuscript. AF contributed to the concept and design, supervised the project, researched and analyzed the data, and wrote and reviewed the manuscript. FS analyzed the data, and wrote and reviewed the manuscript. NF was the study coordinator, researched the data and wrote the manuscript. INP, UA and RAM contributed to the concept and design, analyzed the data and wrote the manuscript. $A B$ is the guarantor.

Funding This research received no specific grant from any funding agency in the public, commercial or not-for-profit sectors.

Competing interests None declared.

Ethics approval Baqai Institute of Diabetology and Endocrinology IRB.

Provenance and peer review Not commissioned; internally peer reviewed.

Data sharing statement Patient level data and full data set are available from the first author at abdulbasit@bideonline.com.

Open Access This is an Open Access article distributed in accordance with the Creative Commons Attribution Non Commercial (CC BY-NC 4.0) license, which permits others to distribute, remix, adapt, build upon this work noncommercially, and license their derivative works on different terms, provided the original work is properly cited and the use is non-commercial. See: http:// creativecommons.org/licenses/by-nc/4.0/

\section{REFERENCES}

1. Abbott CA, Malik RA, van Ross ER, et al. Prevalence and characteristics of painful diabetic neuropathy in a large communitybased diabetic population in the U.K. Diabetes care 2011;34:2220-4.

2. Tesfaye S, Vileikyte L, Rayman G, et al. Painful diabetic peripheral neuropathy: consensus recommendations on diagnosis, assessment and management. Diabetes Metab Res Rev 2011;27:629-38.

3. Sadosky A, Schaefer C, Mann R, et al. Burden of illness associated with painful diabetic peripheral neuropathy among adults seeking treatment in the US: results from a retrospective chart review and cross-sectional survey. Diabetes Metab Syndr Obes 2013;6:79-92.

4. Tesfaye S, Boulton AJ, Dyck PJ, et al. Diabetic neuropathies: update on definitions, diagnostic criteria, estimation of severity, and treatments. Diabetes Care 2010;33:2285-93.

5. Bril V, England J, Franklin GM, et al, American Academy of Neurology, American Association of Neuromuscular and Electrodiagnostic Medicine, American Academy of Physical Medicine and Rehabilitation. Evidence-based guideline: treatment of painful diabetic neuropathy: report of the American Academy of Neurology, the American Association of Neuromuscular and Electrodiagnostic Medicine, and the American Academy of Physical Medicine and Rehabilitation. Neurology 2011;76:1758-65. 
6. Tesfaye S, Wilhelm S, Lledo A, et al. Duloxetine and pregabalin: high-dose monotherapy or their combination? The "COMBO-DN study"-a multinational, randomized, double-blind, parallel-group study in patients with diabetic peripheral neuropathic pain. Pain 2013;154:2616-25.

7. Wilkinson ID, Selvarajah D, Greig M, et al. Magnetic resonance imaging of the central nervous system in diabetic neuropathy. Curr Diab Rep 2013;13:509-16.

8. Oyibo SO, Prasad YD, Jackson NJ, et al. The relationship between blood glucose excursions and painful diabetic peripheral neuropathy: a pilot study. Diabet Med 2002;19:870-3.

9. Bierhaus A, Fleming T, Stoyanov S, et al. Methylglyoxal modification of Nav1.8 facilitates nociceptive neuron firing and causes hyperalgesia in diabetic neuropathy. Nat Med 2012;18:926-33.

10. Soderstrom LH, Johnson SP, Diaz VA, et al. Association between vitamin $\mathrm{D}$ and diabetic neuropathy in a nationally representative sample: results from 2001-2004 NHANES. Diabet Med 2012;29:50-5.

11. Shehab D, Al-Jarallah K, Mojiminiyi OA, et al. Does vitamin D deficiency play a role in peripheral neuropathy in type 2 diabetes? Diabet Med 2012;29:43-9.

12. Alamdari A, Mozafari R, Tafakhori A, et al. An inverse association between serum vitamin $D$ levels with the presence and severity of impaired nerve conduction velocity and large fiber peripheral neuropathy in diabetic subjects. Neurol Sci 2015;36:1121-6.

13. Maser RE, Lenhard MJ, Pohlig RT. Vitamin D insufficiency is associated with reduced parasympathetic nerve fiber function in type 2 diabetes. Endocr Pract 2015;21:174-81.

14. Lv WS, Zhao WJ, Gong SL, et al. Serum 25-hydroxyvitamin D levels and peripheral neuropathy in patients with type 2 diabetes: a systematic review and meta-analysis. J Endocrinol Invest 2015;38:513-18.

15. Celikbilek A, Gocmen AY, Tanik N, et al. Decreased serum vitamin $D$ levels are associated with diabetic peripheral neuropathy in a rura area of Turkey. Acta Neurol Belg 2015;115:47-52.

16. Herrmann M, Sullivan DR, Veillard AS, et al. Serum 25-hydroxyvitamin D: a predictor of macrovascular and microvascular complications in patients with type 2 diabetes. Diabetes Care 2015;38:521-8.

17. Hirani V. Vitamin D status and pain: analysis from the Health Survey for England among English adults aged 65 years and over. $\mathrm{Br} \mathrm{J}$ Nutr 2012;107:1080-4.

18. Tague SE, Smith PG. Vitamin D receptor and enzyme expression in dorsal root ganglia of adult female rats: modulation by ovarian hormones. J Chem Neuroanat 2011;41:1-12.

19. Tague SE, Clarke GL, Winter MK, et al. Vitamin D deficiency promotes skeletal muscle hypersensitivity and sensory hyperinnervation. J Neurosci 2011;31:13728-38.

20. Hellweg R, Wohrle M, Hartung HD, et al. Diabetes mellitusassociated decrease in nerve growth factor levels is reversed by allogeneic pancreatic islet transplantation. Neurosci Lett 1991;125:1-4.

21. Anand $\mathrm{P}$, Terenghi $\mathrm{G}$, Warner $\mathrm{G}$, et al. The role of endogenous nerve growth factor in human diabetic neuropathy. Nat Med 1996;2:703-7.

22. Fukuoka $\mathrm{M}$, Sakurai $\mathrm{K}$, Ohta $\mathrm{T}$, et al. Tacalcitol, an active vitamin $\mathrm{D} 3$, induces nerve growth factor production in human epidermal keratinocytes. Skin Pharmacol Appl Skin Physiol 2001;14:226-33.

23. Wergeland S, Torkildsen O, Myhr KM, et al. Dietary vitamin D3 supplements reduce demyelination in the cuprizone model. PLoS ONE 2011;6:e26262.
24. Bianco J, Gueye $\mathrm{Y}$, Marqueste $\mathrm{T}$, et al. Vitamin $\mathrm{D}(3)$ improves respiratory adjustment to fatigue and $\mathrm{H}$-reflex responses in paraplegic adult rats. Neuroscience 2011;188:182-92.

25. Lee $P$, Chen R. Vitamin $D$ as an analgesic for patients with type 2 diabetes and neuropathic pain. Arch Intern Med 2008;168:771-2.

26. Shehab D, Al-Jarallah K, Abdella N, et al. Prospective evaluation of the effect of short-term oral vitamin D supplementation on peripheral neuropathy in type 2 diabetes mellitus. Med Princ Pract 2015;24:250-6.

27. Hawker GA, Mian S, Kendzerska T, et al. Measures of adult pain: Visual Analog Scale for Pain (VAS Pain), Numeric Rating Scale for Pain (NRS Pain), McGill Pain Questionnaire (MPQ), Short-Form McGill Pain Questionnaire (SF-MPQ), Chronic Pain Grade Scale (CPGS), Short Form-36 Bodily Pain Scale (SF-36 BPS), and Measure of Intermittent and Constant Osteoarthritis Pain (ICOAP). Arthritis Care Res (Hoboken) 2011;63(Suppl 11):S240-52.

28. Cipriani C, Romagnoli E, Scillitani A, et al. Effect of a single oral dose of 600,000 IU of cholecalciferol on serum calciotropic hormones in young subjects with vitamin $D$ deficiency: a prospective intervention study. J Clin Endocrinol Metab 2010;95:4771-7.

29. Adams JS, Hewison M. Update in vitamin D. J Clin Endocrinol Metab 2010;95:471-8.

30. Iqbal R, Jafri L, Haroon A, et al. Illuminating the dark side-vitamin D status in different localities of Karachi. J Coll Physicians Surg Pak 2013;23:604-6.

31. Khan $A H$, lqbal $R$, Naureen $G$, et al. Prevalence of vitamin $D$ deficiency and its correlates: results of a community-based study conducted in Karachi, Pakistan. Arch Osteoporos 2012;7:275-82.

32. Mansoor S, Habib A, Ghani F, et al. Prevalence and significance of vitamin $D$ deficiency and insufficiency among apparently healthy adults. Clin Biochem 2010;43:1431-5.

33. Shaheen S, Noor SS, Barakzai Q. Serum alkaline phosphatase screening for vitamin D deficiency states. J Coll Physicians Surg Pak 2012:22:424-7.

34. Sheikh A, Saeed Z, Jafri SA, et al. Vitamin D levels in asymptomatic adults-a population survey in Karachi, Pakistan. PLOS ONE 2012;7:e33452.

35. Tavakoli M, Asghar O, Alam U, et al. Novel insights on diagnosis, cause and treatment of diabetic neuropathy: focus on painful diabetic neuropathy. Ther Adv Endocrinol Metab 2010;1:69-88.

36. Valensi $\mathrm{P}$, Le Devehat $\mathrm{C}$, Richard JL, et al. A multicenter, double-blind, safety study of QR-333 for the treatment of symptomatic diabetic peripheral neuropathy. A preliminary report. $J$ Diabetes Complications 2005;19:247-53.

37. Bell DS. Reversal of the symptoms of diabetic neuropathy through correction of vitamin $\mathrm{D}$ deficiency in a type 1 diabetic patient. Case Rep Endocrinol 2012;2012:165056.

38. Girgis CM, Clifton-Bligh RJ, Hamrick MW, et al. The roles of vitamin $D$ in skeletal muscle: form, function, and metabolism. Endocr Rev 2013;34:33-83.

39. Riaz $\mathrm{S}$, Malcangio $\mathrm{M}$, Miller $\mathrm{M}$, et al. A vitamin $\mathrm{D}(3)$ derivative (CB1093) induces nerve growth factor and prevents neurotrophic deficits in streptozotocin-diabetic rats. Diabetologia 1999;42:1308-13.

40. Dalgard C, Petersen MS, Weihe $\mathrm{P}$, et al. Vitamin D status in relation to glucose metabolism and type 2 diabetes in septuagenarians. Diabetes care 2011;34:1284-8.

41. Alam U, Najam O, Al-Himdani S, et al. Marked vitamin D deficiency in patients with diabetes in the UK: ethnic and seasonal differences and an association with dyslipidaemia. Diabet Med 2012;29:1343-5. 